\title{
Experimental Investigation of Vibration Suppression for Avoiding Bridge Collapse by Pendulum Type Passive Tuned Mass Damping System
}

\author{
N. Nandakumar ${ }^{1}$, Premkumar B ${ }^{2}$, M Santhosh $^{3}$, I. Mohamed Akbarali ${ }^{4}$ \\ Department of Mechanical Engineering, Government College of Technology, Coimabatore 641013 \\ Tamil Nadu.
}

\begin{abstract}
In recent years, many bridges were deformed or collapsed due to flood, lack of maintenance, design flaws, external loads caused by wind, overloading due to vehicle weight, piling work near the bridges, construction error. These loads induce the exciting vibration in the bridge, if the exciting vibration reaches the natural frequency of the bridge, it leads to resonance. At resonance the bridge will vibrate which causes deformation and collapse. To avoid the collapse, the exciting frequency does not affect the bridge. Aim of this project is to reduce the exciting frequency with short period of time duration by adding the external damping system in it. In this project, the simple and compound tuned mass damping system are used to reduce the bridge exciting vibration and find the deformation at the bridges with and without damping system. Both the analysis results and experimental results shows the reduction in the vibration when the system contains the damping system. By this experiments, the exciting vibration is expected to carried by the damping system without deforming the bridge. The modal analysis has prepared for finding the natural frequency of the bridges. The bridge model has prepared by the Catia V5R15.
\end{abstract}

Keywords- Vibration, bridge collapse, pendulum type tuned mass damping system, modal analysis, algadoo's software. TMD-Tuned Mass Damping System, PTMD-Pendulum Type Tuned Mass Damping System.

\section{INTRODUCTON}

In recent years, many bridge collapse happens in India such as Majerhat Bridge Collapse at Kolkata in 2018, Vivekananda flyover at Kolkata 2016, pedestrian bridge collapses Mumbai in 2017, Varanasi Bridge Collapsed at Varanasi in 2018. These bridges were deformed or collapsed due to flood, lack of maintenance, design flaws, external loads caused by wind, overloading due to vehicle weight, piling work near the bridges, construction error. These induce the exciting vibration of the bridge which leads to deformation of the bridge at resonance condition. In the present work, the pendulum type tuned mass damping system (PTMD) will be used to reduce the vibration happens in the bridges. These exciting vibration will be observed by the damping system in short period of time without damage the bridge. A tuned mass damper (TMD), also known as a harmonic absorber or seismic damper, is a device mounted in structures to reduce the amplitude of mechanical vibrations. Their application can prevent discomfort, damage, or outright structural failure. They are frequently used in power transmission, automobiles, and buildings. The two types of tuned mass damping system are spring-mass tuned mass damping, pendulum type tuned mass damping. A tuned pendulum mass damper was included in the early phase of the design to decrease the wind-induced motion of the building by about $50 \%$.

A tuned mass damper (TMD), also known as a harmonic absorber or seismic damper, is a device mounted in structures to reduce the amplitude of mechanical vibrations. Their application can prevent discomfort, damage, or outright structural failure. They are frequently used in power transmission, automobiles, and buildings. Tuned mass dampers stabilize against violent motion caused by harmonic vibration. The practical systems are tuned to either move the main mode away from a troubling excitation frequency, or to add damping to a resonance that is difficult or expensive to damp directly. Examples of this type of vibration are pulling a child back on a swing and letting it go, or hitting a tuning fork and letting it ring.

Forced vibration is when a time-varying disturbance (load, displacement or velocity) is applied to a mechanical system. The disturbance can be a periodic and steady-state input, a transient input, or a random input. The periodic input can be a harmonic or a non-harmonic disturbance.

simple pendulum type tuned mass is used with the bearings which can be eliminated by supporting the mass with cables which allow the system to behave as a simple pendulum attached to a floor. Movement of the floor excites the pendulum. The relative motion of the pendulum produces a horizontal force that opposes the floor motion.

The rigid link moves in phase with the damper and has the same displacement amplitude. The equivalent stiffness is $\mathrm{Wd} / 2 \mathrm{~L}$, and it follows that the effective length is equal to $2 \mathrm{~L}$. Each additional link increases the effective length by $\mathrm{L}$.

The tower, located in Osaka, Japan, is $157 \mathrm{~m}$ high and $28 \mathrm{~m}$ by $67 \mathrm{~m}$ in plan, weighs 44000 metric tons, and has a fundamental period of approximately $4 \mathrm{~s}$ in the north south direction and $3 \mathrm{~s}$ in the east-west direction. 


\section{METHODOLOGY}

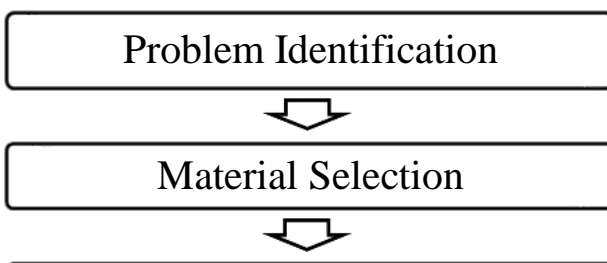

Selection of modeling dimensions

ए

modeling of bridges with and without damping system

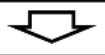

Modal analysis of bridge with and without pendulum type tuned mass damping system.

प

simulation of pendulum type tuned mass damping system.

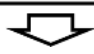

Experimental investigation of pendulum type tuned mass damping system in bridge model.

\section{긴}

Comparison of Analysis and experimental results

Results and conclusions

Fig. 1—Methodology flow chart

\section{MODELLING}

Modelling of bridge with and without damping part system:

Table 1: Dimensions of bridge.

\begin{tabular}{|c|c|}
\hline PART DIMENSIONS & VALUE (in m) \\
\hline Width of the beam & 20 \\
\hline Length of the beam & 60 \\
\hline Thickness of the beam & 5 \\
\hline Width of the support & 20 \\
\hline Length of the support & 10 \\
\hline
\end{tabular}

\section{Model of normal bridge}

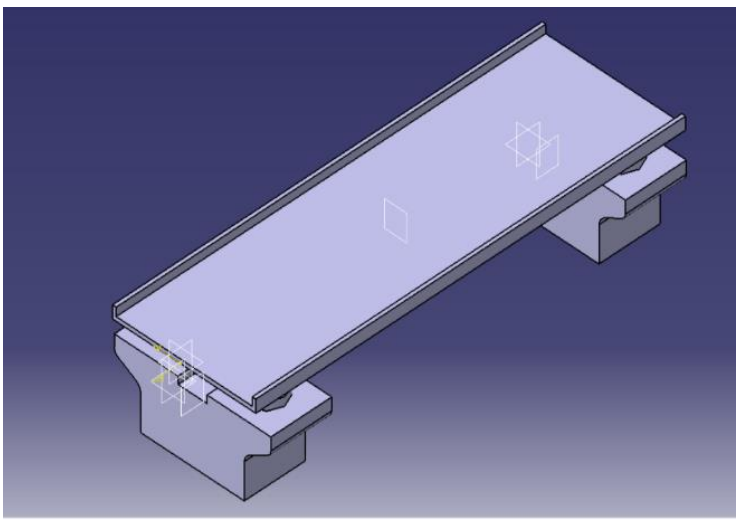

Fig. 2: Model of normal bridge.

\section{Model of normal bridge for analysis}

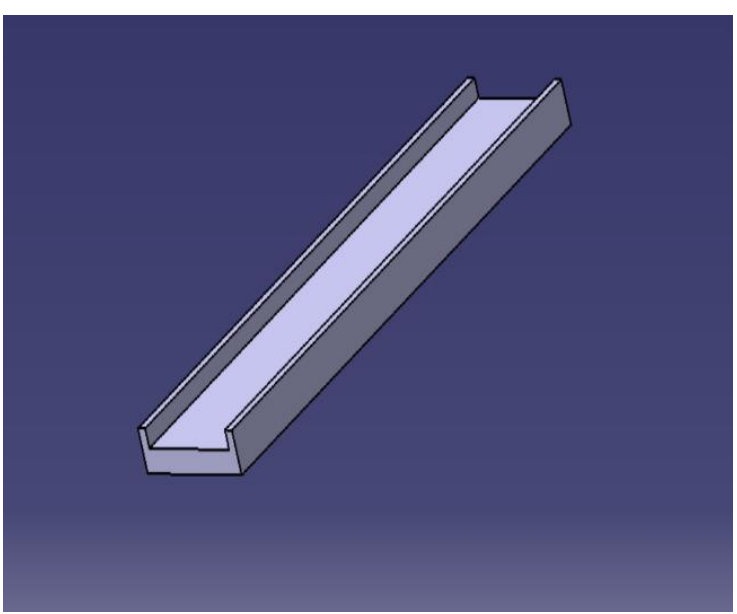

Fig. 3: Model of normal bridge for analysis.

\section{Model of bridge with damping system}

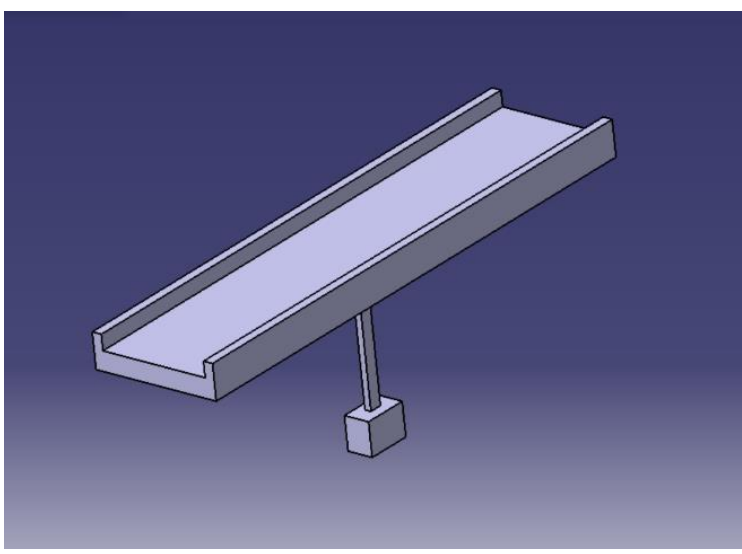

Fig. 4: Model of bridge with simple pendulum type tuned mass damping system. 


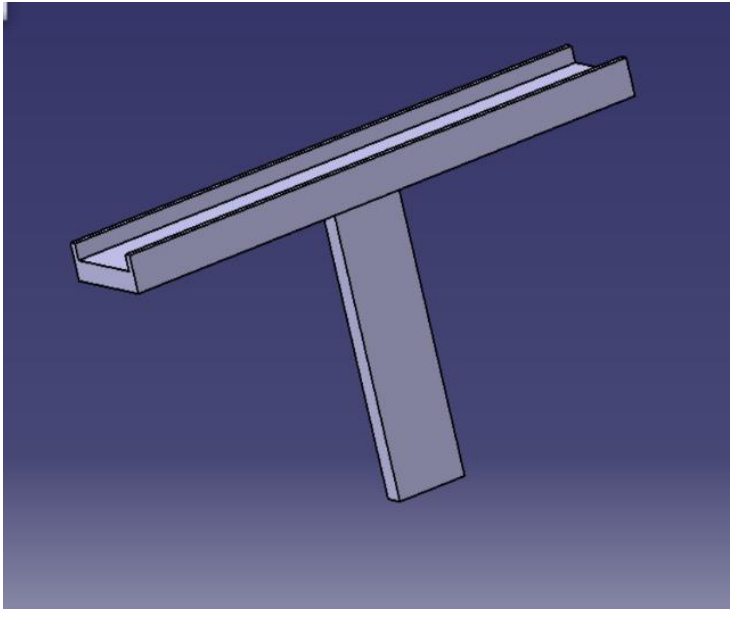

Fig.5: Model of bridge with compound pendulum type tuned mass damping system.

\section{SIMULATION}

\section{Simulation of pendulum type tuned mass damping system:}

Algadoo's graphical user interface (GUI) incorporates several movable toolbars generated around the edges of the screen including the top menu toolbar, the browser toolbar, the tool options toolbar, the simulation controls/environment toolbar, and the properties toolbar. ${ }^{[7]}$ The user with the options to change language; run tutorials; browse and save scenes; find and share scenes online; draw, edit, and interact with scenes; zoom in and out; play and pause the simulation; undo and redo; turn on/off gravity, air friction, and a background grid;. The required tools are Brush tool (B) - used to draw shapes with brush strokes. Circle tool (C) - used to create circles. Drag tool (D) - used to move objects while the simulation is running. Tracer tool (E) - used to attach a tracer to an object (which draws the path of where that object has travelled). Fixate tool (F) - used to weld an object to the object behind it or the background. Knife tool (T) - used to cut polygons along a drawn line. Box tool (X) - used to create rectangles (or squares with SHIFT).

Table 2: Simulation of compound pendulum type tuned mass damping system.

\begin{tabular}{|c|c|c|c|}
\hline S.NO & SPECIFICATION & PENDULUM MODEL & CALCULATION \\
\hline 1 & $\begin{array}{l}\text { Mass=5kg. } \\
\text { Material=steel. } \\
\text { Air friction }=0.74 . \\
\text { Length of pendulum= } 3 \mathrm{~m} .\end{array}$ & & $\begin{array}{l}\mathrm{T}=\text { time taken for } 10 \text { oscillation } / \text { number } \\
\text { of oscillation. } \\
\mathrm{T}=19 / 10=1.9 \text { Secs. } \\
\text { Frequency, } \mathrm{f}=1 / \mathrm{T} \quad 1 / 1.9=0.5 \mathrm{~Hz}\end{array}$ \\
\hline 2 & $\begin{array}{l}\text { Mass }=5 \mathrm{~kg} . \\
\text { Material=steel. } \\
\text { Air friction }=0.74 \text {. } \\
\text { Length of pendulum }=2 \mathrm{~m} \text {. }\end{array}$ & & $\begin{array}{l}\mathrm{T}=\text { time taken for } 10 \text { oscillation/number } \\
\text { of oscillation. } \\
\mathrm{T}=16 / 10=1.6 \text { Secs. } \\
\text { Frequency, } \\
1 / 1.6=0.625 \mathrm{~Hz} .\end{array}$ \\
\hline
\end{tabular}




\begin{tabular}{|l|l|l|l|}
\hline 3 & $\begin{array}{l}\text { Mass=5kg. } \\
\text { Material=steel. } \\
\text { Air friction=0.74. } \\
\text { Length of pendulum=1m. }\end{array}$
\end{tabular}

Table 3: Simulation of compound pendulum type tuned mass damping system.

\begin{tabular}{|c|c|c|c|}
\hline S.NO & SPECIFICATION & PENDULUM MODEL & CALCULATION \\
\hline 1 & $\begin{array}{l}\text { Mass of ball=5kg. } \\
\text { Material=steel. } \\
\text { Air friction=0.74. } \\
\begin{array}{l}\text { Length of } \\
\text { pendulum }=3 \mathrm{~m} .\end{array}\end{array}$ & & $\begin{array}{l}\mathrm{T}=\text { time taken for } 10 \text { oscillation/number of } \\
\text { oscillation. } \\
\mathrm{T}=24 / 10=2.4 \mathrm{Secs} \text {. } \\
\text { Frequency, } \mathrm{f}=1 / \mathrm{T} \\
1 / 2.4=0.416 \mathrm{~Hz}\end{array}$ \\
\hline 2 & $\begin{array}{l}\text { Mass of ball=5kg. } \\
\text { Material=steel. } \\
\text { Air friction= }=0.74 \text {. } \\
\text { Length of } \\
\text { pendulum }=2 \mathrm{~m} .\end{array}$ & & $\begin{array}{l}\mathrm{T}=\text { time taken for } 10 \text { oscillation/number of } \\
\text { oscillation. } \\
\mathrm{T}=19 / 10=1.9 \text { Secs. } \\
\text { Frequency, } \mathrm{f}=1 / \mathrm{T}\end{array}$ \\
\hline 3 & $\begin{array}{l}\text { Mass of the ball=5kg. } \\
\text { Material=steel. } \\
\text { Air friction= }=0.74 \text {. } \\
\text { Length of } \\
\text { pendulum }=1 \mathrm{~m} .\end{array}$ & & $\begin{array}{l}\mathrm{T}=\text { time taken for } 10 \text { oscillation/number of } \\
\text { oscillation. } \\
\mathrm{T}=14 / 10=1.4 \text { Secs. } \\
\text { Frequency, } \mathrm{f}=1 / \mathrm{T}\end{array}$ \\
\hline
\end{tabular}

In the compound pendulum type tuned mass damping system, when increasing the length of the pendulum, it increases the frequency as well as decreases the time period. In the simple pendulum type tuned mass damping system also happens the same. But when compared to compound pendulum, the simple pendulum oscillates 
more time period and it takes all vibration from the bridge. When compared to compound pendulum, the simple pendulum didn't give any deformation and twisting moment to the bridge. The algadoo's simulation software was helpful to simulate the different pendulum at various conditions. From the simulation, it is observed that the best suitable pendulum type was simple pendulum type tuned mass damping system with larger distance.

\section{EXPERIMENTAL SETUP}

\section{Experimental procedure}

In this experiment the pendulum type tuned mass damping system was made by wood board and wood strips. The vibration from the wood bridge modal was measured by the accelerometer which is connected with the Arduino UNO board. The accelerometer is connected with the Arduino UNO board with the help of jump wires. The Arduino UNO board is connected with the system with the help of USB cable. These are the electronic gadgets which are used to make the experimental setup of the bridge model.

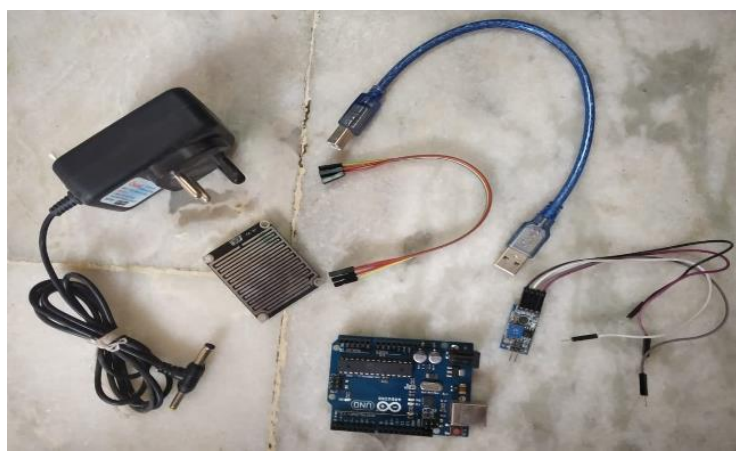

Fig 6: Required electronic equipment.

In the modal analysis of different pendulum type at various condition considered as simply supported beam. The loading condition of the beam is at the centre of the beam. In this analysis, the number of frequencies which gives modes of the bridges deformations were considered as 10 . The modal analysis of the beam shows the natural frequency of the bridge and its corresponding deformation. Based on the requirements, the number of modes and mode shape will be change.

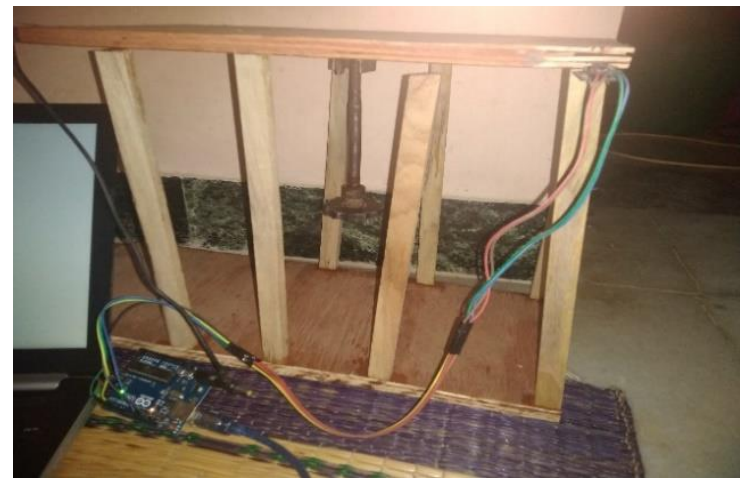

Fig 7: Experimental setup
The following graph shows that bridge model with damping system and without damping system. The bridge without damping system shows that irregular deviation and the bridge with damping system gives regular variation. It shows that the bridge doesn't undergo any deformation. In this experimental setup, the bridge model was made with the help of wood and the wood model was damped with the simple pendulum type tuned mass damping system by the hinge support. The damping and undamping was provided by the tightening and loosening the hinge.

\section{RESULTS AND DISCUSSION}

\section{MODAL ANALYSIS}

Table 4: Modal analysis parameters for bridges

\begin{tabular}{|l|l|}
\hline INPUT PARAMETRS & $\begin{array}{l}\text { CONDITIONS AND } \\
\text { VALUES }\end{array}$ \\
\hline Support condition & $\begin{array}{l}\text { Simply supported } \\
\text { beam. }\end{array}$ \\
\hline Load condition & $\begin{array}{l}\text { Uniformly distributed } \\
\text { load }\end{array}$ \\
\hline Number of modes & 10 \\
\hline
\end{tabular}

\section{Modal analysis of normal bridge}

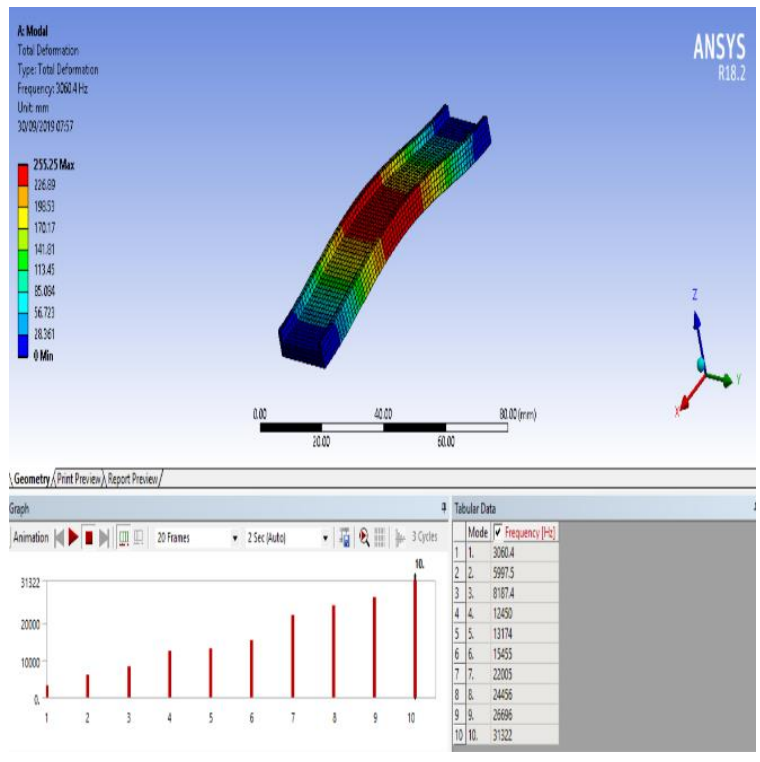

Fig 8: Modal analysis of the bridge.

The frequency of the normal bridge under modal analysis at simply supported condition was ranges from $3060 \mathrm{~Hz}$ to $31322 \mathrm{~Hz}$. The above fig 8 shows that the modal analysis of the normal bridge. The deformation of the bridge was ranges from $28.321 \mathrm{~mm}$ to $255 \mathrm{~mm}$. The maximum deformation occurs at the centre of the bridges. There is no twisting moment of the beam. 


\section{Modal analysis of bridge with compound pendulum type tuned mass damping system}

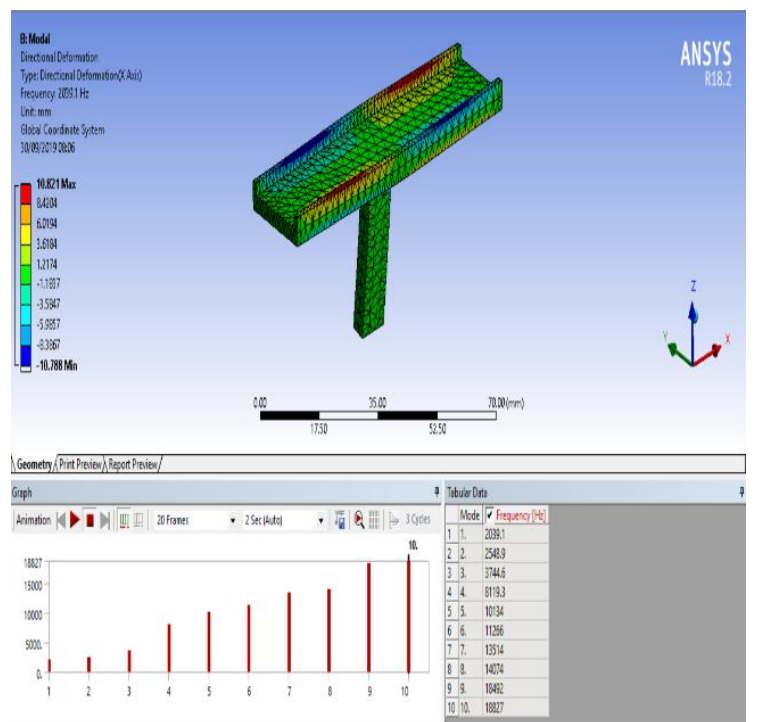

Fig 9: Modal analysis of the bridge with compound pendulum type tuned mass damping system

The frequency of the bridge with compound pendulum type tuned mass damping system under modal analysis at simply supported condition was ranges from $2040 \mathrm{~Hz}$ to $18827 \mathrm{~Hz}$. The above fig 9 shows that the Modal analysis of the bridge with compound pendulum type tuned mass damping system. The deformation of the bridge was ranges from $-10.788 \mathrm{~mm}$ to $10.821 \mathrm{~mm}$. The maximum deformation occurs at the edge of the bridges. It also gives the twisting moment of the beam. It causes the deformation of the bridge.

\section{Modal analysis of bridge with simple pendulum type tuned mass damping system}

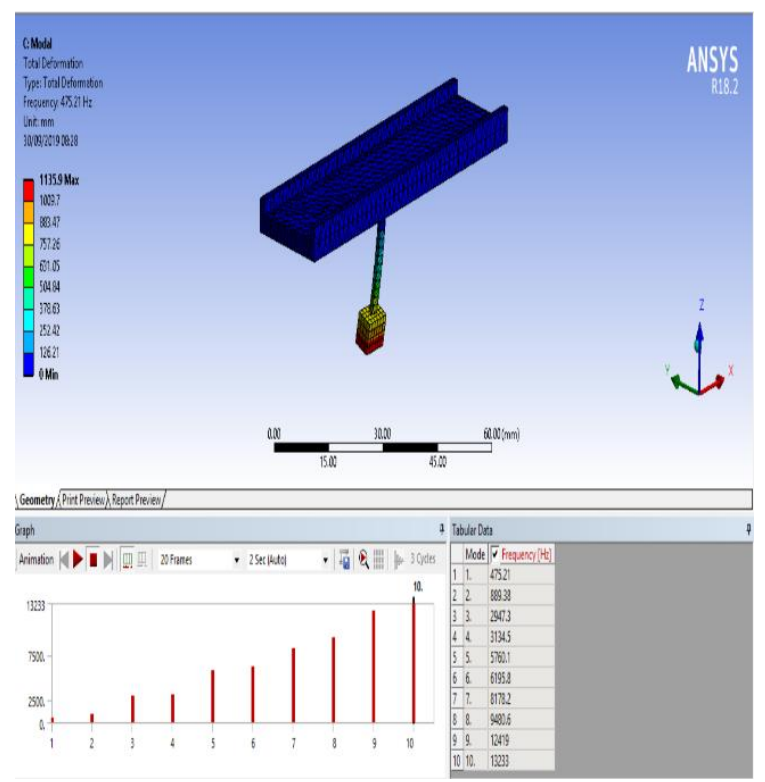

Fig 10: Modal analysis of the bridge with simple pendulum type tuned mass damping system
The frequency of the bridge with simple pendulum type tuned mass damping system under modal analysis at simply supported condition was ranges from $475.21 \mathrm{~Hz}$ to $13233 \mathrm{~Hz}$. The above fig 10 shows that the Modal analysis of the bridge with compound pendulum type tuned mass damping system. The deformation of the bridge was ranges from $0 \mathrm{~mm}$ to $1096 \mathrm{~mm}$. The maximum deformation occurs at the edge of the simple pendulum. So there is no deformation at the bridge. There is no twisting moment of the beam.

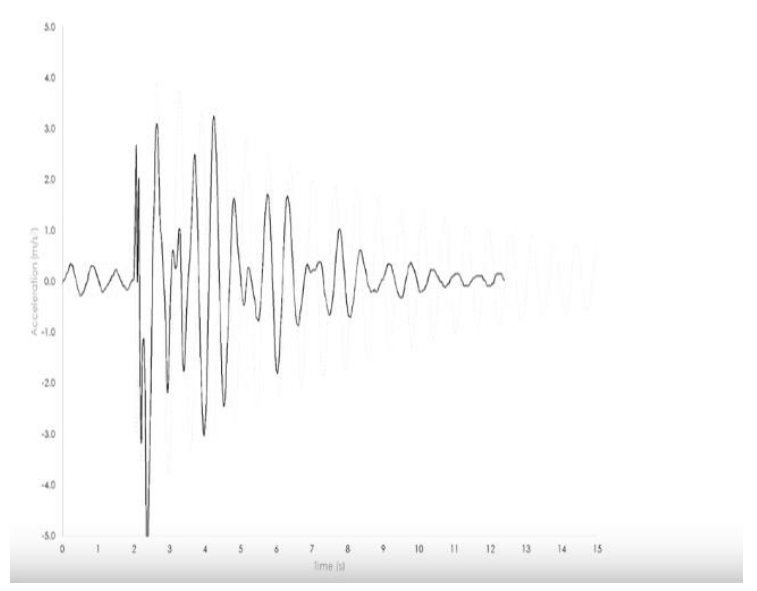

Fig 11: Graph for bridge model without damping system.

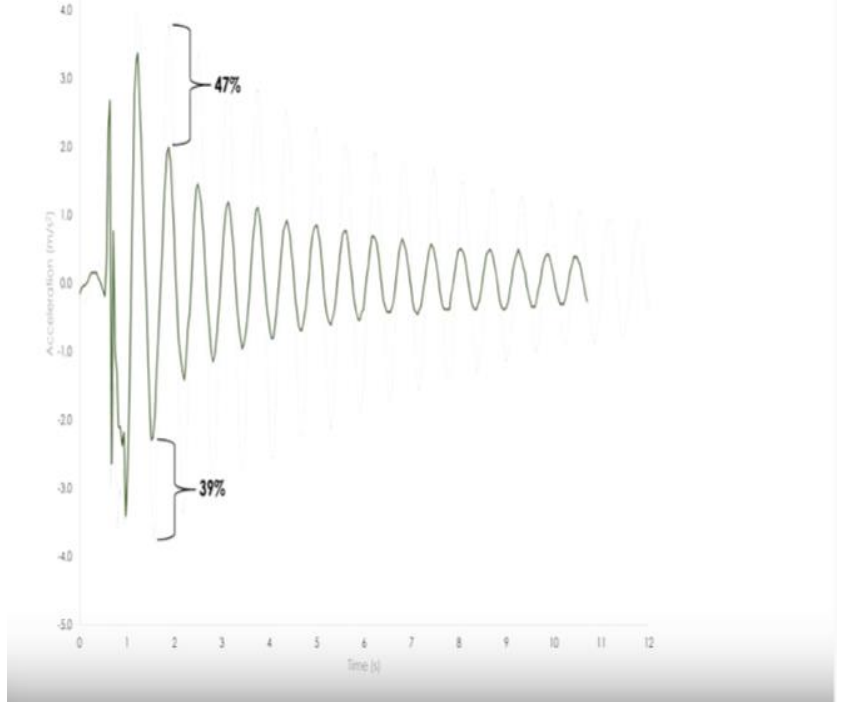

Fig 11: Graph for bridge model without damping system.

In bridge model with damping system the vibration amplitude reduces up to 40 percent when compared to normal bridge model. These graphs were obtained from the accelerometer which passes through the Arduino UNO towards the system. In damping system also, the bridge 
experience the initial irregular variation. The frequency amplitude provides regular variation in simple pendulum damping system when compared to system without damping. By using the amplitude of the frequency it was easy to calculate the damping factor.

In damping system, the upper amplitude of the frequency reduces up to 47 percent and the lower amplitude of the frequency reduces up to 39 percent. The irregular variation gives vibration to the bridges.

From the Modal analysis of bridges with various conditions. The frequency of the normal bridge under modal analysis at simply supported condition was ranges from $3060 \mathrm{~Hz}$ to $31322 \mathrm{~Hz}$. The deformation of the bridge was ranges from $28.321 \mathrm{~mm}$ to $255 \mathrm{~mm}$. The maximum deformation occurs at the centre of the bridges. There is no twisting moment of the beam. The frequency of the bridge with compound pendulum type tuned mass damping system under modal analysis at simply supported condition was ranges from $2040 \mathrm{~Hz}$ to $18827 \mathrm{~Hz}$. The deformation of the bridge was ranges from $-10.788 \mathrm{~mm}$ to $10.821 \mathrm{~mm}$. The maximum deformation occurs at the edge of the bridges. It also gives the twisting moment of the beam. The frequency of the bridge with simple pendulum type tuned mass damping system under modal analysis at simply supported condition was ranges from $475.21 \mathrm{~Hz}$ to $13233 \mathrm{~Hz}$. The maximum deformation occurs at the edge of the simple pendulum. So there is no deformation at the bridge. There is no twisting moment of the beam. In experimental setup the vibration amplitude reduces up to 40 percent when compared to normal bridge model.

\section{CONCLUSION}

In this project, the simple and compound tuned mass damping system are used to reduce the bridge exciting vibration. The modal analysis has prepared for finding the deformation at the bridges with and without damping system. The analysis result is compared with the experimental results. By this experiments, the exciting vibration is expected to carried by the damping system without deforming the bridge. The present work of investigating the vibration suppression for avoiding bridge collapse by pendulum type passive tuned mass damping system has been successfully reducing the deformation and twisting moment of the bridge when implementing the simple pendulum type tuned mass damping system than that of compound pendulum type tuned mass damping system. This experiment shows that when bridge is damped with simple pendulum type tuned mass damping system will not deform and oscillate the bridge. By using this damping system in bridges will avoid the collapse in future. In future, the bridge collapse can be reduced by implementing the different kinds of damping system. The damping efficiency can be altered by changing the length of the pendulum by active tuned mass damping system. In active type, the length of the pendulum automatically changed based on the vibration experienced by the bridge.

\section{REFERENCES}

[1] Roffel, A. J., Narasimhan, S., \& Haskett, T. (2012). Condition Assessment of a In-Service Pendulum Tuned Mass Damper In Structures Congress 2012 (pp. 1661-1672).

[2] Iwabuki, H., Fukada, S., Osafune, T., Shimura, M., \& Sasaki, E. (2019). Contribution of large-vehicle vibration and bridge vibration to low-frequency noise generation. Applied Acoustics, 155, 150-166.

[3] Pakos, W., \& Grosel, J. (2019). Reduction of cable vibrations in a cable stayed bridge under biharmonicexcitation. Engineering Structures, 189, 1-10.

[4] Liang, L., Li, X., Yin, J., Wang, D., Gao, W., \& Guo, Z. (2019). Vibration characteristics of damping pad floating slab on the longspan steel truss cable-stayed bridge in urban rail transit. Engineering Structures, 191, 92-103.

[5] Androus, A., Afefy, H. M., \& Sennah, K. (2017). Investigation of free vibration and ultimate behavior of composite twin-box girder bridges. Journal of ConstructionalSteel Research, 130, 177-192.

[6] Cantero, D., Hester, D., \& Brownjohn, J. (2017). Evolution of bridge frequencies and modes of vibration during truck passage. Engineering Structures, 152, 452-464.

[7] Wardhana, K., \& Hadipriono, F. C. (2003). Analysis of recent bridge failures in the United States. Journal of performance of constructed facilities, 17(3), 144-150.

[8] Miguel, L. F., Lopez, R. H., Torii, A. J., Miguel, L. F., \& Beck, A. T. (2016). Robust design optimization of TMDs in vehiclebridge coupled vibration problems. Engineering Structures, 126, 703-711.

[9] Wang, L., Kang, X., \& Jiang, P. (2016). Vibration analysis of a multi- span continuous bridge subject to complex traffic loading and vehicle dynamic interaction. KSCE Journal of Civil Engineering, 20(1), 323-332.

[10] Wang, L., Shi, W., \& Zhou, Y. (2019). Study on self-adjustable variable pendulum tuned mass damper. The Structural of Tall and Buildings, 28(1)

[11] Wang, J. F., Lin, C. C., \& Chen, B. L. (2003). Vibration suppression for high-speed railway bridges using tuned mass dampers. International Journal of Solids and structures, 40(2), 465-491

[12] Lazar, I. F., Neild, S. A., \& Wagg, D. J. (2016). Vibration suppression of Cables using tuned inerter dampers. Engineering Structures, 122, 62-71.

[13] Wang, W., Wang, X., Hua, X., Song, G., \& Chen, Z. (2018). Vibration control of vortex-induced vibrations of a bridge deck by a single-side pounding tuned mass damper. Engineering Structures, 173, 61-75.

[14] Dai, J., Xu, Z. D., \& Gai, P. P. (2019). Tuned mass-damper-inerter control of wind-induced vibration of flexible structures based on inerter location. Engineering Structures, 199, 109585.

[15] Jo, B. W., Tae, G. H., \& Lee, D. W. (2001). Structural vibration of tuned mass damper-installed three-span steel box bridge. International journal of pressure vessels andpiping, 78(10), 667-675.

[16] Hemmati, A., Oterkus, E., \& Khorasanchi, M. (2019). Vibration suppression of offshore wind turbine foundations using tuned liquid column dampers and tuned mass dampers. Ocean Engineering, 172, 286-295.

[17] Shi, W., Wang, L., Lu, Z., \& Wang, H. (2019). Experimental and numerical study on adaptive-passive variable mass tuned mass damper. Journal of Sound andVibration, 452, 97-111.

[18] Yucel, M., Bekdaş, G., Nigdeli, S. M., \& Sevgen, S. (2019). Estimation of optimum tuned mass damper parameters via machine learning. Journal of Building Engineering, 26, 100847.

[19] Pais, T., \& Boote, D. (2017). Developments of Tuned Mass Damper for yacht structures. Ocean Engineering, 141, 249-264.

[20] Lu, Z., Li, K., Ouyang, Y., \& Shan, J. (2018). Performance-based optimal design of tuned impact damper for seismically excited nonlinear building. Engineering Structures, 160, 314-327. 